\title{
Prospects and perspectives of virtual in-vitro toxicity studies on herbal extracts of Terminalia arjuna with enhanced stratagem in Artemia salina model: A panacea to explicit the credence of solvent system in brine shrimp lethality bioassay
}

\author{
D. K. Meena', A. K. Sahoo', H. S. Swain', S. Borah1, P. P. Srivastava², N. P. Sahu², B. K. Das* \\ ${ }^{1}$ ICAR-Central Inland Fisheries Research Institute, Barrackpore, Kolkata-700120, India, ${ }^{2}$ ICAR-Central Institute of Fisheries Education, \\ Mumbai-400061, India
}

\section{A B S T R A C T}

An in-vitro toxicity study was undertaken for the validation, laydown the standards, supplement some of the information on assessment and define the nature of toxicity of different solvent extracts of Terminalia arjuna considering Artemia salina model, as a case study. In the present study, experimental conditions such as yellow color light of $100 \mathrm{~W}$ at $5 \%$ salinity for 48 hours with pH $8.0-8.5$ at $30{ }^{\circ} \mathrm{C}$, picking up of nauplii with $3 \mathrm{~mL}$ dropper cut at its tip, 24 hours incubation in same experimental conditions and visualization with $50 X$ magnifying glass were modified unlike previous studies. Functional screening of solvent extracts with their mother solvents revealed that hex, Etac, Chlo, Acet, Etoh, and Meoh exhibited, the LC $_{50}$ values as $118.50,101.75,93.36,278.32,528.78$ and 477.67 ppm, respectively, designating them as; medium, medium, high, medium, low, medium toxic, while in their solvent extract forms the toxicity nature gets changed indicating the effectiveness of the extracts. Study, also defines the toxicity level for universal solvents such as DMSO and Dw as to be non-toxic as per the Meyers toxicity index and Clarkson's toxicity criterion. Among solvent extracts of $T$. arjuna, all were found to be toxic as per Meyers toxicity index. However, with reference to Clarkson's toxicity criterion, solvent extracts comprehended extended toxicity classes as low, medium and high toxic. The PCA 1 and 2 showed, $69.46 \%$ and $19.74 \%$ variations indicating strong correlation between the parameters. The results confirmed that $\mathrm{LC}_{50}$ of any solvent extract could be treated as relative $\mathrm{LC}_{50}$, which is the fraction of mother solvent and could be treated as absolute $\mathrm{LC}_{50}$, which is the actual potential of the solvent extracts that might be positive for less effective and negative for highly effective solvent extracts. For smoothening of experimental results, negative sign was ignored. Relative $\mathrm{LC}_{50}$, relative $\mathrm{LC}_{50} \%$, absolute $\mathrm{LC}_{50}$, and absolute $\mathrm{LC}_{50} \%$ could find liner relation with their \% fractions and inverse relation with their counterparts. Thus present study advocates the inclusion of relative $\mathrm{LC}_{50}$, relative $\mathrm{LC}_{50} \%$, absolute $\mathrm{LC}_{50}$, absolute $\mathrm{LC}_{50} \%, \mathrm{considerating}$ $95 \%$ upper and lower fiducial class intervals and TI values while fixing the nature of toxicity and designating the safety aspect to the host. Also, the study recommends for the collective effort to make BSLA as an internationally accepted and robust standard by revisiting and supplementing the existing toxicity criterion for the BSLA.

Keywords: BSLA; DMSO and T. arjuna solvents extracts; Relative and absolute $\mathrm{LC}_{50}$; Toxicity index and criterion; $\mathrm{TI}$

\section{INTRODUCTION}

Medicinal plants are considered the origin of the many therapeutic agents and novel drugs. In developing countries the medicinal plants are serving primary source of their health care. As per WHO (2007), major world populace (70-80\%) are depending on plant based unconventional medicament as a primary treatment for the illness(Countries like China and India are serving as knowledge partner globally in disseminating the ethno-medicinal data base on the medicinal plants. Although, medicinal plants are known to exhibit the excellent medical properties, some of them are possessing toxicants characteristics as well. India is considered as varietal emporium and having the richest diversity of medicinal plants. The Terminalia arjuna an important medicinal plant distributed around the world, has proved its strong foothold in terms of antimicrobial, antiinflammatory, anti-oxidant, anti-diuretic and allergic and 
excellent homemade remedy for chronic cardiac ailments since ancient Ayurveda time. Despite of multifarious health benefits of $T$. arjuna it has not been explored scientifically for its toxicological properties and safe level of the solvent extracts for designing the novel drugs except some remote study on this aspect i.e. Suely et al. (2015) has reported that $80 \%$ ethanolic bark extract of T. arjuna was found to possess piscicidal effects on Clarius batrachus fish but has not confirmed with brine shrimp lethality test. Similarly, Bhatt et al. (2016) has screened only two solvent extracts (ethanolic and aqueous) and revealed the $\mathrm{LC}_{50} \%$ as 20 and $10 \mu \mathrm{g} / \mathrm{mL}$ for ethanolic and aqueous hot extracts, respectively, at $1000 \mu \mathrm{g} / \mathrm{mL}$. Toxicity of the plants extract are credence to the bioactive components. The toxicity of plants extracts has been assessed since long time by conventional approaches such as in-vivo and in-vitro toxicity studies taking other animals as model, and thereafter Artemia salina was mostly (90\%) used as model animal out of other species of the Artemia genus (Campbell et al., 1994). Owing to animal ethical concern in toxicity assessment experiment, there is need for alternate animal models. For evaluating the efficacy of the brine shrimp lethality assay (BSLA), a comaparative study between the $\mathrm{LC}_{50}$ data of Artemia salina and acute toxicity in rats and mice was performed (Parra et al., 2001; Sharma et al., 2013; Naidu et al., 2014)). Since, its inception, BSLA was adopted one amongst the user friendly strategy due to its beneficial aspects i.e. wider adaptability starting from herbal material (Meyer et al., 1982; McLaughlin et al., 1998a; Moshi et al., 2010; Ogugu et al., 2012; Gadir, 2012; Solanki and Selvanayagam, 2013; Sharma et al., 2013), toxicity of heavy metals (Sleet and Brendel, 1985; Martínez et al., 1999), to all the way for nano-particles (Maurer- Jones et al., 2013), heavy metals (Sleet and Brendel, 1985; Martínez et al., 1999) and metal ions (Kokkali et al., 2011, materials for dental applications (Pelka et al., 2000), and toxicity assessment of marine algae and cyanobacteria before bio-prospecting (Jaki et al., 1999; Mayorga et al., 2010; Carballo et al., 2002); toxicity of environmental media such as wastewater (Manfra et al., 2011), seawater (Manfra et al., 2010) and marine discharges (Nunes et al., 2006). Further, this is a simple, user friendly, economical, rapid, low requirement to startup (Hamidi et al., 2014), and bibliographic studies showed its competency and reliability in establishing correlation between the $\mathrm{LC}_{50}$ values ascertained in BSLA deploying brine shrimp and the outcomes from the mice model, adopting short-term toxicity assessment through oral mode of treatment (Parra et al., 2001; Arlsanyolu and Erdemgil, 2006) bioassay as compare to their chemical and biological (MT'T cell assay, zebra fish model) counter parts. Also, bio-markers and teratogenic substances, due to lower sensitivity are assumed to impose less impact in acute toxicity. (Yu and Lu, 2018). In addition, higher sensitivity towards contaminant and stressful condition standout Artemia salina model as one of versatile one among other invertebrates (Van and Persoone, 1993). US Environmental Protection Agency (US EPA 1983) has documented by the Artemia salina ideal invertebrate for toxicological studies and and production checking. In spite of robustness of BSLA, some of the factors found to exhibit pragmatic role in deciding the efficacy and reliability of this assay. For instances, i), the mother solvents in which the test extract are prepared, play an orchestral dynamic in terms of toxicity of the herbal products. Some of the most commonly used organic solvent and detergents are reported to encompass high cyto-toxicity in vivo (Wu, 2014). Past studies showed DMSO, Tween-20, Nikkol (Wu, 2014) as solvents of choice and revealed maximum toxicity in as'Tween-20, and apparently, DMSO and Nikkol designated as safe solvents but none of the study has conducted to evaluate the limit of toxicants and congruence of the solvents with combined toxicity of herbal products. ii) proper experimental design for drug delivery so that the interferences by these synthetic compounds can be abducted. Particularly, negative control group should be taken in consideration keeping that negative control can possess lesser amount of mother solvents. For real time value of toxicity, the value of solvents are to be deducted from the test samples. iii), the stage of Artemia to be used, as after hatching of Artemia cysts, past works showed a random selection of the stage to be used that inculcate the false or pseudo results. But references suggest that instar II-III could exhibit maximum sensitivity towards teratogenic substances (Vanhaecke et al., (1981) just after it exhausts its yolk sac. iv), the hatching and experimental conditions like $\mathrm{pH}$, salinity, light, aeration, color and duration. v), selection of the appropriate and potential solvent of choice because the efficacy of herbal material greatly depends on the credence of solvent systems attributable to the bioactive principles. vi) optimization of various criterion of toxicity assessment such as behavioral studies and hatching ability but these can also give false results because of the not uniformity of uptake dose of toxicant by the nauplii incubated, and inference due to other factor which can also cause the erratic behavioral changes and swimming pattern during course of toxicity studies. Endpoints, observation by changes in behavioral activities such as irratic or interrupted swimming could have a prospective application in the establishment of electronic based technology. Image capturing and recording can be used for studying behavioral changes in thye organisms. Artemia spp. have been used since long time for landscaping of toxicants used in toxicological experiments (Dvorak et al., 2012), therefore, due to lack of stringent and globally accepted protocol, brine shrimp species could be utilized for assessment of the toxicity. In this back drop, an experiment was executed to stream line BSLA 
for maximizing its sensitivity for carry out the plethora of toxicity studies taking solvent extracts of T. arjuna as a case study with consideration of its ethno-medicinal importance. Thus, the aim of above investigation is to validate earlier standards and laydown some principles that might be beneficial for toxicity and fortify some newer outcomes of the studies for making the BSLA more stringent and reliable toxicity assessment method.

\section{MATERIALS AND METHODS}

\section{Preparation of artificial sea water and hatching of the Artemia salina}

As the most important aspect for hatching of Artemia cysts is the salt water. For preparing artificial sea water, initially, $150 \mathrm{~g}$ of $200 \mathrm{~g} \mathrm{(5 \% )}$ common salt was added to the $4 \mathrm{~L}$ distilled and rest of $50 \mathrm{~g}$ was added next day water and mixed and filtered through fine mesh net of muslin cloth to removed extraneous material. To this $1 \mathrm{~g}$ Artemia cyst was added into two $5 \mathrm{~L}$ capacity of cylindrical glass jar containing $4 \mathrm{~L}$ of water kept for obtaining the desired size and density (Fig. 1).

In these steps the inclusion of total quantity of salt required in two installments facilitates the size homogeneity of nauplii of Artemia salina which is very much important form the success of the experiment point of view. After providing, the $100 \mathrm{~W}$ capacity bulbs flashing yellowish light for enhancing the hatching success and proper aeration, the mouth of the jar was tightened with small mesh size net and kept the jars under observation. After 36 hours the active hatching started and up to 48 hours the hatching was observed.

\section{Preparation of the extracts}

In the present study, the serial extraction was performed using same dry powder with different solvent based on their polarity. The extracts were prepared both in their mother solvents and DMSO at the stock concentration of 10, 20, 30, 40 and $50 \mathrm{ppm}$. The solvent extracts were

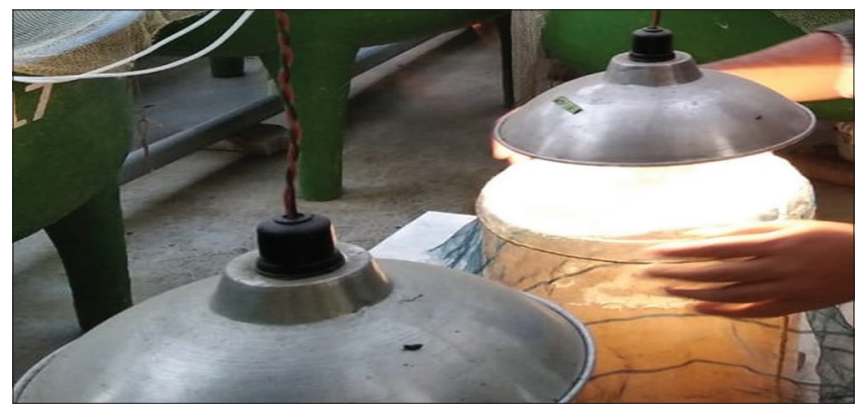

Fig 1. Set-up of Artemia salina hatching unit. The intervention includes in-terms of coloration, light flux, salinity, $\mathrm{pH}$ and temperature for ascertaining hatching, activity of 48 hours old Instar II nauplii of $A$. salina with maintaining size homogeneity. The experimental conditions were as follows: yellow color light of $100 \mathrm{v}$ at $5 \%$ salinity for 48 hours with $\mathrm{pH}$ 8.0-8.5 at $30^{\circ} \mathrm{C}$, during hatching. kept in amber glass sample container of $10 \mathrm{~mL}$ capacity to protect the bioactive constituents from oxidation and other chemical reactions.

\section{Experimental set up and standardization of the experimental conditions}

First of all, the mother solvents i.e. hexane, ethyl acetate, chloroform, acetone, ethanol, methanol, distilled water and reference solvent medium DMSO were taken for fixing the $\mathrm{LC}_{50}$ values. Briefly, in a $50 \mathrm{~mL}$ capacity sample container (Tarson) 30 nauplii of Artemia salina container were added and 100-500 $\mu \mathrm{L}$ respective mother solvents were also added and incubated for 24 hours under $100 \mathrm{~W}$ yellow light and thereafter mortality was observed by taking no motion nauplii as dead and it was confirmed by visualizing under $50 \mathrm{X}$ magnifying glass (Fig. 2).

The mortality was noted in all treatment groups. This is most important steps as lesson learnt from the previous studies and by trial and error method. The naulii of Artemia salina of more than 48 hours old after achieving the instar II stage were taken into a $500 \mathrm{~mL}$ capacity beaker and thereafter with the help of $2 \mathrm{~mL}$ dropper which edge was cut with scissor to make it more convenient to pick the nauplii of Artemia salina in desired number in one go. For study purpose, the $4 \mathrm{~L}$ salt was also prepared in same manner as prepared for hatching the nauplii except whole calculated amount of salt was poured at time to make it $5 \%$ solution. For screening the T. arjuna solvent extracts, the conditions were followed as mentioned above and after putting nauplii into the $50 \mathrm{~mL}$ salt water, from the stock vials $500 \mu \mathrm{L}$ was added (following fixed volume percentage method) to each container. The experiment was repeated thrice for confirmation with two elution mediums (mother solvent and DMSO) as mentioned and numbers of dead nauplii were noted against the treatment groups.

Estimation of $\mathrm{LC}_{50}$, relative $\mathrm{LC}_{50} \%$, absolute $\mathrm{LC}_{50}$, absolute $\mathbf{L C}_{50} \%$ and fixing the toxicity level

The $\mathrm{LC}_{50}$ was estimated using $\mathrm{Graph}$ pad prism v.8.1.3 with excel sheet and percentage relative $\mathrm{LC}_{50}$ and percentage
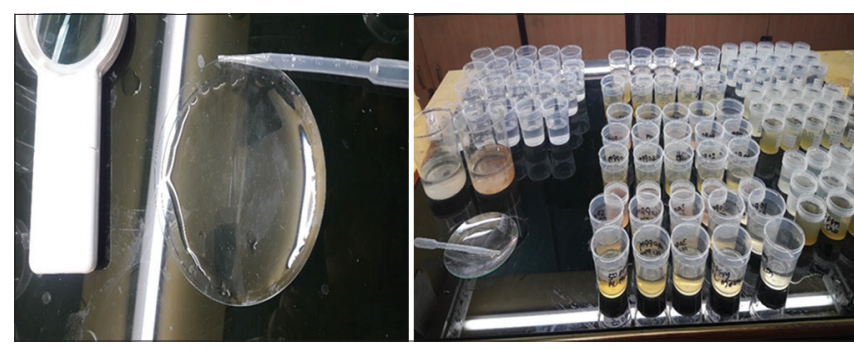

Fig 2. Showing experimental set up and accessories. The in-vivo study was conducted in laboratory for incubation in $50 \mathrm{~mL}$ capacity sample containers and the nauplii picked up with the help of $3 \mathrm{~mL}$ dropper that cuts at the tip and $50 \mathrm{X}$ magnifying glass was used to visualized the dead and alive nauplii upon 24 hours incubation. 
absolute $\mathrm{LC}_{50}$ was calculated by the following formula considering the combined toxicity and absolute toxicity for assessing the actual toxicity of the particular solvent extract.

Relative $\mathrm{LC}_{50}(\%)=$ Combined $\mathrm{LC}_{50} / \mathrm{LC}_{50}$ of a solvent or solvent extract $* 100$

Absolute $\mathrm{LC}_{50}(\%)=$ Mother solvent $\mathrm{LC}_{50}-$ Relative $\mathrm{LC}_{50}$

Based on the $\mathrm{LC}_{50}$ values, the toxicity nature was fixed referring standard toxicity indices given by Meyer's and Clarkson's As per the Meyer's toxicity classes extracts with $\mathrm{LC}_{50}<1000 \mu \mathrm{g} / \mathrm{mL}$ (toxic), and $\mathrm{LC}_{50}>1000 \mu \mathrm{g} / \mathrm{mL}$ (non-toxic)non-toxic (Meyer et al., 1982).

Clarkson's claasified as follows: $\mathrm{LC}_{50}$ above $1000 \mu \mathrm{g} / \mathrm{mL}$ (toxic), $\mathrm{LC}_{50} 500$ - $1000 \mu \mathrm{g} / \mathrm{mL}$ (low toxic), $\mathrm{LC}_{50} 100-500 \mu \mathrm{g} / \mathrm{mL}$ (medium toxic), and $\mathrm{LC}_{50} 0-100 \mu \mathrm{g} / \mathrm{mL}$ (highly toxic) (Clarkson et al., 2004).

\section{RESULTS}

\section{Experimental set up and standardization of the experimental conditions}

The improved experimental conditions such as salinity, light duration, color and intensity have better toxicity assessment. The $5 \%$ common salt water showed size uniformity and validate the duration for obtaining the instar II stage after 48 hours. The yellow light source of $100 \mathrm{~W}$ induces the activity of nauplii that reduces the chances of experimental error because the dose of solvent extract would pursuit better to the active nauplii that can be easily assessed for the mortality. Similarly, pH and temperature were kept $7^{\circ} \mathrm{C}$ and $30^{\circ} \mathrm{C}$ for entire experimental period starting form cysts hatching to end of the toxicity assessment would result in better survival and robustness to the nauplii.

Estimation of $\mathrm{LC}_{50}$, absolute $\mathrm{LC}_{50}$, absolute $\mathrm{LC}_{50} \%$, relative $\mathbf{L C}_{50} \%$, and fixing the toxicity level

Fig. 3, briefly illustrates, the comparative toxicological parameters of mother solvent extracts and DMSO solvent extracts. The mother solvents and DMSO are being plotted on $\mathrm{X}$-axis while primary $\mathrm{Y}-1$ axis and primary $\mathrm{Y}-2$ axis showing $\mathrm{LC}_{50}$ value and $\mathrm{R}^{2}$ values for the respective solvent systems.

The $\mathrm{LC}_{50}$ values for mother solvents and DMSO in ascending order can be presented as Dw $(1081.30 \mu \mathrm{g} / \mathrm{mL})$ $>$ DMSO $(1029.00 \mu \mathrm{g} / \mathrm{mL})>$ Etoh $(528.78 \mu \mathrm{g} / \mathrm{mL})>$ Meoh $(477.67 \mu \mathrm{g} / \mathrm{mL})>\operatorname{Acet}(278.32 \mu \mathrm{g} / \mathrm{mL})>\operatorname{Hex}(118.51 \mu \mathrm{g} / \mathrm{mL})$ $>\operatorname{Etac}(101.75 \mu \mathrm{g} / \mathrm{mL})$ and Chlo $(93.36 \mu \mathrm{g} / \mathrm{mL})$. The $95 \%$ upper fiducial class interval were as follows; Dw (1524.11 $\mu \mathrm{g} / \mathrm{mL})$, DMSO (1495.78 $\mu \mathrm{g} / \mathrm{mL})$, Etoh (846.51 $\mu \mathrm{g} / \mathrm{mL})$, Meoh $(840.40 \mu \mathrm{g} / \mathrm{mL})$ and Acet $(552.00 \mu \mathrm{g} / \mathrm{mL})$. Similarly, the $95 \%$ upper fiducial class interval showed same trend for lower 95\% lower fiducial limit. The $\mathrm{R}^{2}$ value of solvents correlated as Hex (0.97) $\geq \operatorname{Acet}(0.97) \geq \operatorname{Etoh}(0.97)>\operatorname{Chlo}(0.96)>\operatorname{Etac}(0.94) \geq$ DMSO (0.94) > Dw (0.93) > Meoh (0.93).

In Fig. 4, the primary $\mathrm{X}$-axis and secondary $\mathrm{X}$-axis showing, the DMSO solvent extracts and mother solvent extracts, respectively. Similarly, primary and secondary $\mathrm{Y}$ - axis, showing $\mathrm{LC}_{50}(\mu \mathrm{g} / \mathrm{mL})$ and relative $\mathrm{LC}_{50} \%$, respectively. The

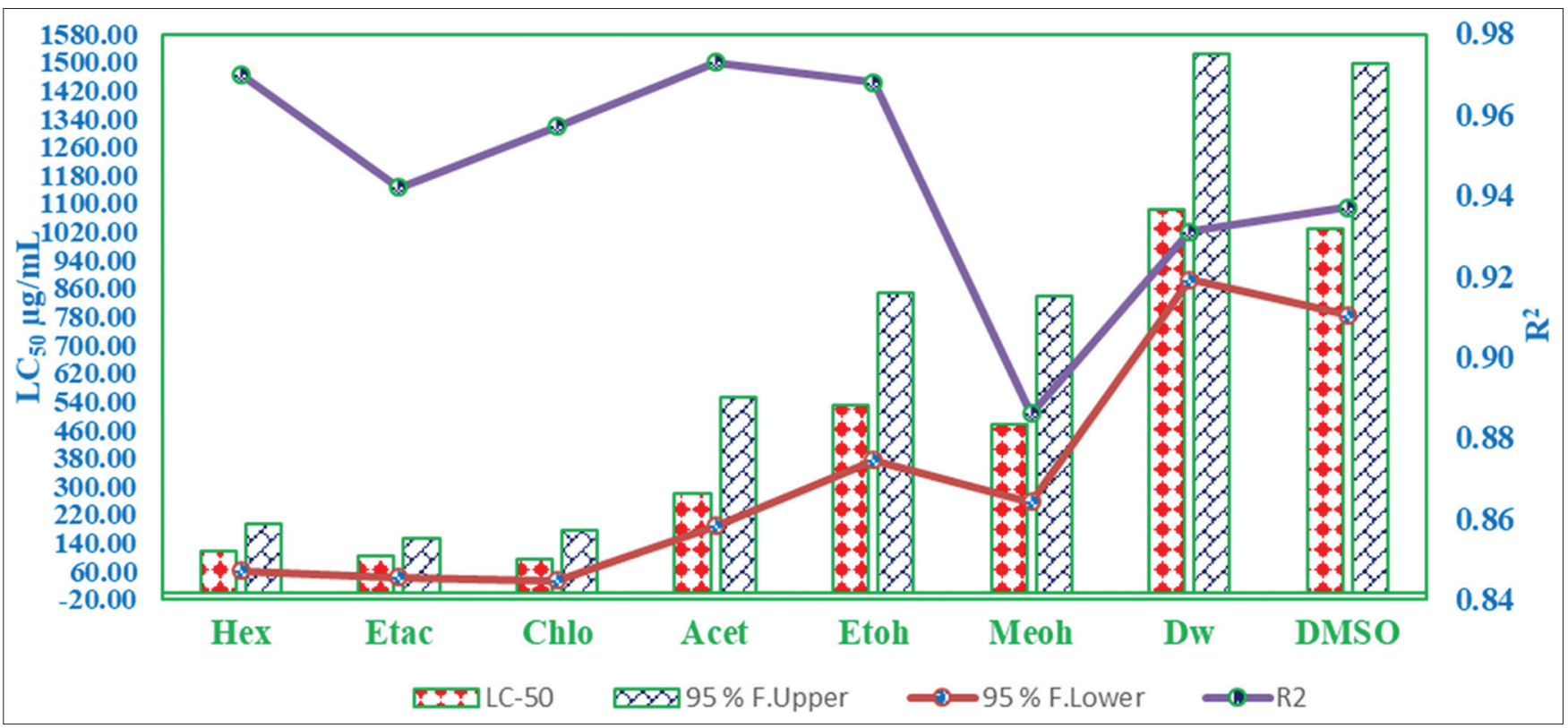

Fig 3. Showing comparative toxicological parameters of mother solvents and DMSO solvent. The mother solvents and DMSO are being plotted on $\mathrm{X}$-axis while primary $\mathrm{Y}-1$ axis and primary $\mathrm{Y}-2$ axis showing $L C_{50}$ value and $\mathrm{R}^{2}$ values for the respective solvent systems. 


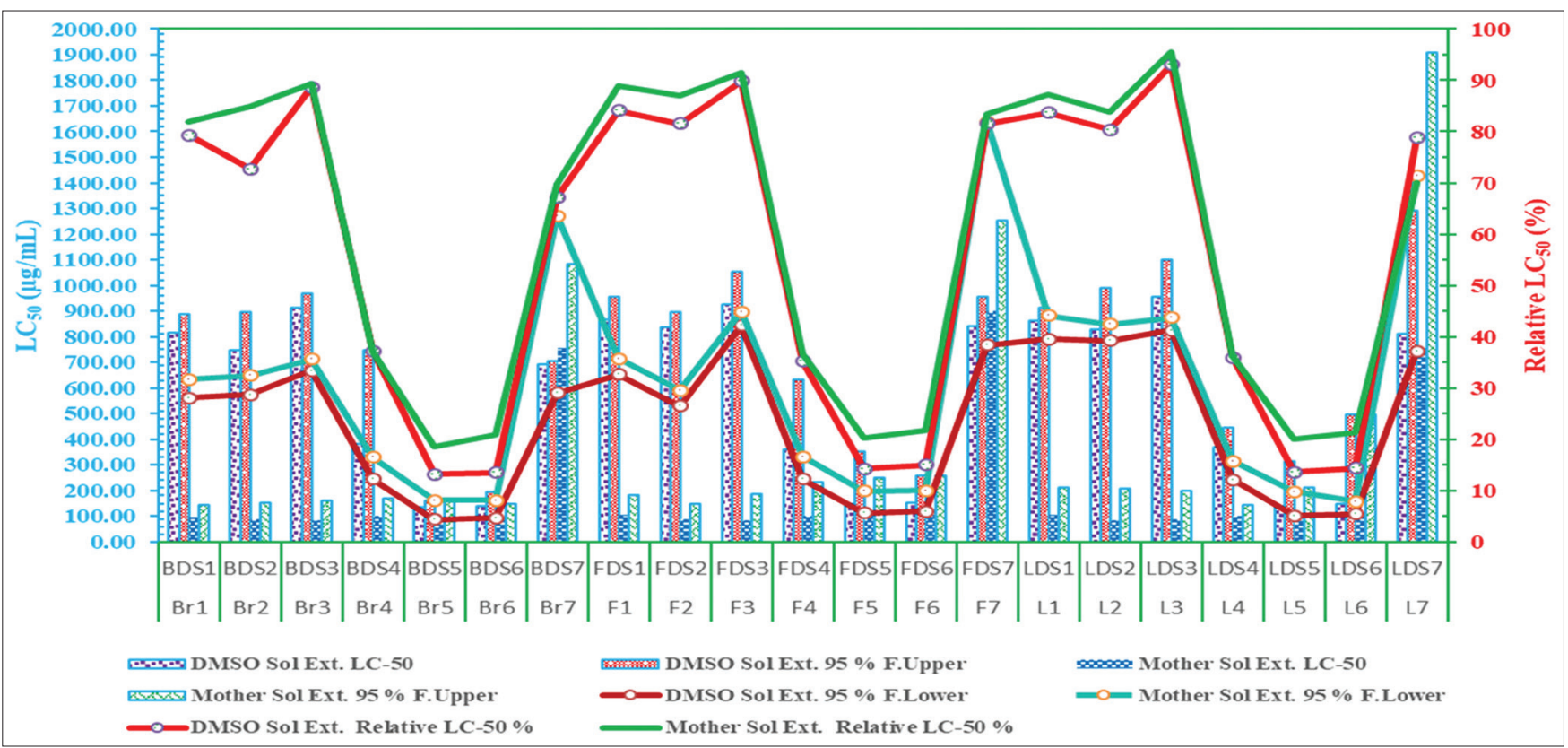

Fig 4. Showing comparative toxicological parameters of mother solvent extracts and DMSO solvent extracts. DMSO solvent extracts and mother solvent extracts were plotted on primary X-axis and secondary X-axis respectively. Similarly, $\mathrm{LC}_{50}(\mu \mathrm{g} / \mathrm{mL})$ and relative $\mathrm{LC}_{50} \%$, was depicted on primary and secondary $\mathrm{Y}$ - axis, respectively.

maximum $\mathrm{LC}_{50}$ among DMSO solvent extracts showed by LDS3 $(957.15 \mu \mathrm{g} / \mathrm{mL})$ followed by FDS3 $(924.07 \mu \mathrm{g} / \mathrm{mL})$, BDS3 $(912.32 \mu \mathrm{g} / \mathrm{mL})$ whereas lowest $\mathrm{LC}_{50}$ showed by BDS5 $(135.99 \mu \mathrm{g} / \mathrm{mL})$ followed by BDS6 $(139.01 \mu \mathrm{g} / \mathrm{mL})$, LDS5 $(139.94 \mu \mathrm{g} / \mathrm{mL})$.

The relative $\mathrm{LC}_{50} \%$ was recorded maximum in L3 $(95.51 \mu \mathrm{g} / \mathrm{mL})$ and LDS3 $(93.01 \mu \mathrm{g} / \mathrm{mL})$ followed by F3 $(91.38 \mu \mathrm{g} / \mathrm{mL})$ and FDS3 $(89.38 \mu \mathrm{g} / \mathrm{mL})$. Among mother solvent extracts, the lowest $\mathrm{LC}_{50}$ was recorded for $\mathrm{Br} 3(83.45 \mu \mathrm{g} / \mathrm{mL})$ followed by $\mathrm{L} 2(85.35 \mu \mathrm{g} / \mathrm{mL}), \mathrm{Br} 2(86.46 \mu \mathrm{g} / \mathrm{mL})$. The maximum $95 \%$ fiducial upper class interval value of $\mathrm{LC}_{50}$ was observed for LDS7 $(1290.23 \mu \mathrm{g} / \mathrm{mL}$ and L7 $(1907.94 \mu \mathrm{g} / \mathrm{mL})$ as DMSO solvent extract and mother solvent extract, respectively. The lowest fiducial class interval was reported for $\operatorname{Br} 5(75.03 \mu \mathrm{g} / \mathrm{mL})$ and BDS5 $(75.03 \mu \mathrm{g} / \mathrm{mL})$.

The reference $\mathrm{LC}_{50}$ values for DMSO solvent extracts were recorded as to be $1029.08 \mu \mathrm{g} / \mathrm{mL}$ and for mother solvent extracts such as Hex, Etac, Chlo, Acet, Etoh, Meoh and $\mathrm{Dw}$, it was, 118.51, 101.75, 93.36, 278.32, 528.78, $1081.30 \mu \mathrm{g} / \mathrm{mL}$, respectively. The maximum relative $\mathrm{LC}_{50}$ for DMSO solvent extracts was found to be as 957.17 for LDS3, followed by FDS3 (924.07) and BDS3 (912.32) and lowest in case of BDS5 (135.99) followed by BDS6 (139.01) and LDS5 (139.94). Among mother solvent extracts, the maximum value for relative $\mathrm{LC}_{50}$ was reported for F7 (900.94) followed by L7 (757.99) and Br7 (755.60) and lowest were noted for Br3 (83.45) followed by F3 (85.31) and $\mathrm{L} 3$ (89.16). The absolute $\mathrm{LC}_{50}$ fraction value is considered as the potential of the solvent extracts. The maximum $\mathrm{LC}_{50}$ fraction among DMSO solvent extracts, was found to be in BDS5 (893.09) followed by BDS6 (890.07), LDS5 (889.14), FDS5 (882.09) and FDS6 (874.71). The \% of relative and absolute $\mathrm{LC}_{50}$ value also followed the same trend, and maximum $\%$ relative $\mathrm{LC}_{50}$ was recorded as 95.51 for $\mathrm{L} 3$ which is followed by F3 (91.38) and Br3 (89.39) and lowest was 18.66 for Br5 followed by L5 (20.00) and F5 (20.31) among mother solvent extracts. While $\%$ absolute $\mathrm{LC}_{50}$ value was maximum in Br5 (81.34) followed by L5 (80.00), F5 (79.69), Br6 (79.03), L6 (78.61) and F6 (78.15) and lowest was 4.49 for L3 followed by F3 (8.62), Br3 (10.61), F1 (11.17) and L1 (12.73) among mother solvent extracts. Among, DMSO solvent extracts maximum value for $\%$ relative $\mathrm{LC}_{50}$ value was recorded in BDS5 (86.79) followed by BDS6 (86.49), LDS5 (86.40) and FDS5 (85.72) whereas lowest was found to be as 4.49 for LDS3 followed by FDS3 (10.20) and BDS3 (10.61).

Table 1. depicting the toxicity levels, nature of mother solvents and their solvent extracts and DMSO and its solvenet extracts. As per Meyer's toxicity index and Clarkson's toxicity criterion, only DMSO and Dw having $\mathrm{LC}_{50}$ value as $1029.08 \mu \mathrm{g} / \mathrm{mL}$ and $1081.30 \mu \mathrm{g} / \mathrm{mL}$, respectively, were found to be non-toxic. As per the Meyers toxicity index, rest of the solvent extract were found to be toxic whereas in Clarkson's toxicity criterion, the toxic compounds are again divided into three categories.i.e. low toxic, medium toxic and highly toxic. According to this criterion, DMSO solvent extract fall under low or medium toxic categories while mother solvent extracts occupied each category 
Meena, et al.

Table 1: Showing the toxicity nature and other toxicological parameters of Mother solvents and DMSO solvent and their solvent extracts

\begin{tabular}{|c|c|c|c|c|c|c|c|}
\hline \multirow[t]{2}{*}{ Extract } & \multirow{2}{*}{$\mathrm{LC}_{50}(\mu \mathrm{g} / \mathrm{mL})$} & \multirow{2}{*}{$\begin{array}{l}\text { Absolute LC } \\
(\mu \mathrm{g} / \mathrm{mL})\end{array}$} & \multirow{2}{*}{$\begin{array}{c}95 \% \text { Fiducial Cl } \\
\text { lower }\end{array}$} & \multirow{2}{*}{$\begin{array}{l}95 \% \text { Fiducial } \\
\mathrm{Cl} \text { upper }\end{array}$} & \multirow[t]{2}{*}{$\mathbf{R}^{2}$} & \multicolumn{2}{|c|}{ Nature of toxicity } \\
\hline & & & & & & $\begin{array}{l}\text { Meyer's toxicity } \\
\text { index }\end{array}$ & $\begin{array}{l}\text { Clarkson's toxicity } \\
\text { criterion }\end{array}$ \\
\hline DMSO & 1029.08 & NA & 436.018 & 1595.78 & 0.93 & non-toxic & ${ }^{*}$ non- toxic \\
\hline BDS1 & 815.91 & 213.17 & 560.91 & 888.91 & 0.99 & toxic & ${ }^{\star \star}$ Iow toxic \\
\hline BDS2 & 748.34 & 280.74 & 574.46 & 894.20 & 0.98 & toxic & ${ }^{* *}$ low toxic \\
\hline BDS3 & 912.32 & 116.75 & 667.71 & 968.94 & 0.95 & toxic & ${ }^{* *}$ low toxic \\
\hline BDS4 & 383.22 & 645.85 & 245.73 & 749.60 & 0.93 & toxic & ${ }^{* *}$ low toxic \\
\hline BDS5 & 135.98 & 893.09 & 87.79 & 159.38 & 0.90 & toxic & ${ }^{\star * \star}$ medium toxic \\
\hline BDS6 & 139.01 & 890.07 & 94.33 & 195.77 & 0.94 & toxic & ${ }^{* * *}$ medium toxic \\
\hline BDS7 & 691.14 & 337.94 & 580.16 & 706.60 & 0.98 & toxic & ${ }^{* *}$ low toxic \\
\hline FDS1 & 864.94 & 164.14 & 653.15 & 955.73 & 0.96 & toxic & ${ }^{* *}$ low toxic \\
\hline FDS2 & 838.72 & 190.35 & 529.20 & 896.07 & 0.94 & toxic & ${ }^{* *}$ low toxic \\
\hline FDS3 & 924.07 & 105.01 & 843.98 & 1051.91 & 0.93 & toxic & ${ }^{* *}$ low toxic \\
\hline FDS4 & 362.63 & 666.45 & 245.60 & 633.85 & 0.94 & toxic & ${ }^{* * *}$ medium toxic \\
\hline FDS5 & 146.98 & 882.09 & 113.98 & 351.91 & 0.93 & toxic & ${ }^{\star * \star}$ medium toxic \\
\hline FDS6 & 154.37 & 874.71 & 120.28 & 260.10 & 0.99 & toxic & ${ }^{* * *}$ medium toxic \\
\hline FDS7 & 839.099 & 189.97 & 768.63 & 954.39 & 0.95 & toxic & ${ }^{* *}$ Iow toxic \\
\hline LDS1 & 860.79 & 168.29 & 790.85 & 911.82 & 0.98 & toxic & ${ }^{* *}$ low toxic \\
\hline LDS2 & 826.76 & 202.31 & 783.93 & 988.78 & 0.97 & toxic & ${ }^{* *}$ Iow toxic \\
\hline LDS3 & 957.15 & 71.92 & 825.36 & 1099.08 & 0.93 & toxic & ${ }^{* *}$ low toxic \\
\hline LDS4 & 369.78 & 659.29 & 242.17 & 443.84 & 0.99 & toxic & ${ }^{\star * \star}$ medium toxic \\
\hline LDS5 & 139.94 & 889.13 & 103.02 & 313.41 & 0.95 & toxic & ${ }^{* * *}$ medium toxic \\
\hline LDS6 & 147.95 & 881.12 & 109.10 & 496.79 & 0.96 & toxic & ${ }^{* * *}$ medium toxic \\
\hline LDS7 & 810.22 & 218.85 & 745.11 & 1290.23 & 0.98 & toxic & ${ }^{* *}$ low toxic \\
\hline Hex & 118.51 & NA & 60.75 & 193.82 & 0.97 & toxic & ${ }^{\star * *}$ medium toxic \\
\hline Etac & 101.74 & NA & 43.74 & 152.78 & 0.94 & toxic & ${ }^{* * *}$ medium toxic \\
\hline Chlo & 93.36 & NA & 35.26 & 274.54 & 0.96 & toxic & 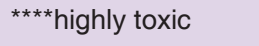 \\
\hline Acet & 278.32 & NA & 88.24 & 551.99 & 0.97 & toxic & ${ }^{* * *}$ medium toxic \\
\hline Etoh & 528.78 & NA & 74.12 & 846.51 & 0.97 & toxic & ${ }^{* *}$ low toxic \\
\hline Meoh & 477.67 & NA & 55.77 & 840.41 & 0.89 & toxic & ${ }^{* * *}$ medium toxic \\
\hline Dw & 1081.29 & NA & 585.21 & 1524.11 & 0.93 & non-toxic & ${ }^{*}$ non-toxic \\
\hline $\mathrm{Br} 1$ & 97.09 & 21.41 & 72.13 & 145.53 & 0.98 & toxic & 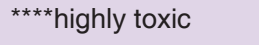 \\
\hline $\mathrm{Br} 2$ & 86.45 & 15.29 & 73.74 & 150.79 & 0.97 & toxic & ${ }^{* \star * * \text { highly toxic }}$ \\
\hline $\mathrm{Br} 3$ & 83.45 & 9.91 & 45.00 & 161.97 & 0.88 & toxic & ${ }^{* * * * \text { highly toxic }}$ \\
\hline $\mathrm{Br} 4$ & 102.87 & 175.47 & 83.52 & 169.30 & 0.95 & toxic & ${ }^{\star * *}$ medium toxic \\
\hline $\mathrm{Br} 5$ & 98.65 & 430.13 & 75.03 & 166.61 & 0.93 & toxic & ${ }^{\star \star \star *}$ highly toxic \\
\hline $\mathrm{Br} 6$ & 100.16 & 377.51 & 66.80 & 147.68 & 0.95 & toxic & 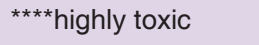 \\
\hline $\mathrm{Br} 7$ & 755.59 & 325.70 & 690.33 & 1084.73 & 0.98 & toxic & ${ }^{* *}$ low toxic \\
\hline $\mathrm{F} 1$ & 105.26 & 13.24 & 61.13 & 181.27 & 0.96 & toxic & ${ }^{* * *}$ medium toxic \\
\hline F2 & 88.45 & 13.28 & 61.69 & 147.36 & 0.91 & toxic & 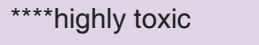 \\
\hline F3 & 85.31 & 8.051 & 54.20 & 186.44 & 0.94 & toxic & ${ }^{* * * * \text { highly toxic }}$ \\
\hline F4 & 102.14 & 176.19 & 85.60 & 233.85 & 0.93 & toxic & $\begin{array}{l}{ }^{* *} \text { closed to highly } \\
\text { toxic/medium toxic }\end{array}$ \\
\hline
\end{tabular}

(Contd...) 
Table 1: (Continued)

\begin{tabular}{|c|c|c|c|c|c|c|c|}
\hline \multirow[t]{2}{*}{ Extract } & \multirow[t]{2}{*}{$\mathrm{LC}_{50}(\mu \mathrm{g} / \mathrm{mL})$} & \multirow{2}{*}{$\begin{array}{l}\text { Absolute LC } \\
(\mu \mathrm{g} / \mathrm{mL})\end{array}$} & \multirow{2}{*}{$\begin{array}{c}95 \% \text { Fiducial Cl } \\
\text { lower }\end{array}$} & \multirow{2}{*}{$\begin{array}{l}95 \% \text { Fiducial } \\
\text { Cl upper }\end{array}$} & \multirow[t]{2}{*}{$\mathbf{R}^{2}$} & \multicolumn{2}{|c|}{ Nature of toxicity } \\
\hline & & & & & & $\begin{array}{l}\text { Meyer's toxicity } \\
\text { index }\end{array}$ & $\begin{array}{l}\text { Clarkson's toxicity } \\
\text { criterion }\end{array}$ \\
\hline F5 & 107.35 & 421.37 & 83.98 & 251.91 & 0.93 & toxic & $\begin{array}{l}{ }^{* * *} \text { closed to highly } \\
\text { toxic/medium toxic }\end{array}$ \\
\hline F6 & 104.35 & 373.31 & 80.28 & 260.10 & 0.98 & toxic & $\begin{array}{l}{ }^{* * *} \text { closed to highly } \\
\text { toxic/medium toxic }\end{array}$ \\
\hline F7 & 900.93 & 180.36 & 868.63 & 1254.39 & 0.95 & toxic & ${ }^{* \star}$ low toxic \\
\hline L1 & 103.42 & 15.08 & 90.85 & 211.82 & 0.98 & toxic & $\begin{array}{l}{ }^{* *} \text { closed to highly } \\
\text { toxic/medium toxic }\end{array}$ \\
\hline L2 & 85.34 & 16.40 & 63.93 & 208.78 & 0.97 & toxic & 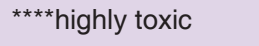 \\
\hline L3 & 89.16 & 4.19 & 48.45 & 199.23 & 0.97 & toxic & ****highly toxic \\
\hline L4 & 100.88 & 177.43 & 72.17 & 143.84 & 0.99 & toxic & ****highly toxic \\
\hline L5 & 105.73 & 423.048 & 93.02 & 213.41 & 0.95 & toxic & $\begin{array}{l}{ }^{* *} \text { closed to highly } \\
\text { toxic/medium toxic }\end{array}$ \\
\hline L6 & 102.19 & 375.48 & 49.10 & 496.79 & 0.96 & toxic & $\begin{array}{l}{ }^{* *} \text { closed to highly } \\
\text { toxic/medium toxic }\end{array}$ \\
\hline L7 & 757.98 & 323.31 & 684.21 & 1907.94 & 0.83 & toxic & low toxic \\
\hline
\end{tabular}

*Indicate the lower value of absolute $\mathrm{LC}_{50}$ as compared to relative $\mathrm{LC}_{50}$; ${ }^{* *}$ indicate the higher value of absolute $\mathrm{LC}_{50}$ as compared to relative $\mathrm{LC}_{50}$

i.e. $\mathrm{Br} 1-\mathrm{Br} 3\left(\mathrm{LC}_{50:}\right.$ 97.09, 86.46, $\left.83.45 \mu \mathrm{g} / \mathrm{mL}\right) ; \mathrm{Br} 5-\mathrm{Br} 6$ $\left(\mathrm{LC}_{50}: 98.65,100.16 \mu \mathrm{g} / \mathrm{mL}\right)$; F1-F2 (LC 50 : 88.46,85.31); L2-L4 $\left(\mathrm{LC}_{50}: 85.35,89.16,100.88\right)$ as highly toxic, and medium toxic or closed to highly toxic were; Br4(102.87), F4-F6 (LC : $\left._{50} 102.13,107.41,104.36 \mu \mathrm{g} / \mathrm{mL}\right)$, L1:103.42,L5-L6 (LC $\left.{ }_{50}: 105.73,102.19 \mu \mathrm{g} / \mathrm{mL}\right)$ whereas $\mathrm{Br} 7, \mathrm{~F} 7$ and L7 were observed to be as low toxic with $\mathrm{LC}_{50}$ value, $755.60,900.94$ and $757.99 \mu \mathrm{g} / \mathrm{mL}$, respectively. Among mother solvents, Hex and Etac (closed to highly toxic), Acet and Meoh were reported to be as medium toxic with $\mathrm{LC}_{50}: 118.51 \mu \mathrm{g} / \mathrm{mL}, 101.75 \mu \mathrm{g} / \mathrm{mL}$, $278.32 \mu \mathrm{g} / \mathrm{mL}$ and $477.67 \mu \mathrm{g} / \mathrm{mL}$, respectively while Chlo: $\mathrm{LC}_{50}, 93.35 \mu \mathrm{g} / \mathrm{mL}$ was found to be highly toxic and Etoh as low toxic $\mathrm{LC}_{50}, 528.78 \mu \mathrm{g} / \mathrm{mL}$.

\section{DISCUSSION}

\section{Prospects}

The BSLA is considered a rapid result generating, reliable, economical and suitable test for toxicity assessment (Meyer et al., 1982). The procedure defines the $\mathrm{LC}_{50}$ values in $\mu \mathrm{g} / \mathrm{mL}$ of bioactive principles of test materials in the salt conditions. The credence of activities of bio-efficient principles and test sustances are demonstrated as to be toxic to shrimps. The past research on the bioassay revealed that it exhibits strong correlation with cytotoxic activity against tumor proliferating tissues in human being, and has directed to the investigation of elite group of usual anti-carcinogenic agents concomitant with ethno-medicinal important plants (McLaughlin et al., 1998). Besides, the bioefficacy of some herbal materials in BSLA, were reported to comprehend strong anti-oxidant potential, anticancer, antitumor, antiparasitic and antimicrobial potential which might be archived to the occurrence of secondary metabolite such as phenolics, flavonoids, terpenoids etc (Lee, 1992; Ren et al., 2003;Tungmunnithum et al., 2018; Aryal et al., 2019). Despite of great scope of BSLA in toxicity assessment, there is presently no internationally accepted standard. For this reason, calibrations with existing standards and continuos upgradation for standardization is highly recommended (Manfra et al., 2015). It has been reported that amongst the commonly used endpoints linking to short-term mortality, long-term mortality, acute mortality, hatchability of cysts and behavioral dynamics were calibrated based on the existing (Manfra et al., 2015), while long-term hatchability calibrated based on Italian standards. Present study highlighted the Toxicity level/nature of different solvent extract of the T. arjuna beneficial ethno-medicinal plant with modification in the existing BSLA. The study complied non-toxic nature of DMSO and Distilled water, however, DMSO was found to retain some toxic activity as compared to the distilled water which is supported with low $\mathrm{LC}_{50}$ value for DMSO that also in accordance to the study of Worthley and Schott (1967) whose study implies that $\mathrm{LC}_{50}$ increment was correspond to the increasing concentration and was found to be significant between $50 \%$ and $25 \%$ incorporation of DMSO. Present study pursuit better results of Artemia salina hatching including active movement and uniform size might be possibly due to alternation in salt dose while preparing artificial sea water and duration, color, temperature and capacity of light that was used and maintained as $100 \mathrm{~W}$ yellow light for 48 hours at $30{ }^{\circ} \mathrm{C}$ with salt water $\mathrm{pH} 8.0-8.5$ that was modified from past studies (Vanhaecke et al., 1980; Guzzella 1997; Artoxkit 2014;Manfra et al., 2016). Libralato et al. (2016) reviewed the changes in previous studies based on trial and error methods and suggested short term (24 h) and long 


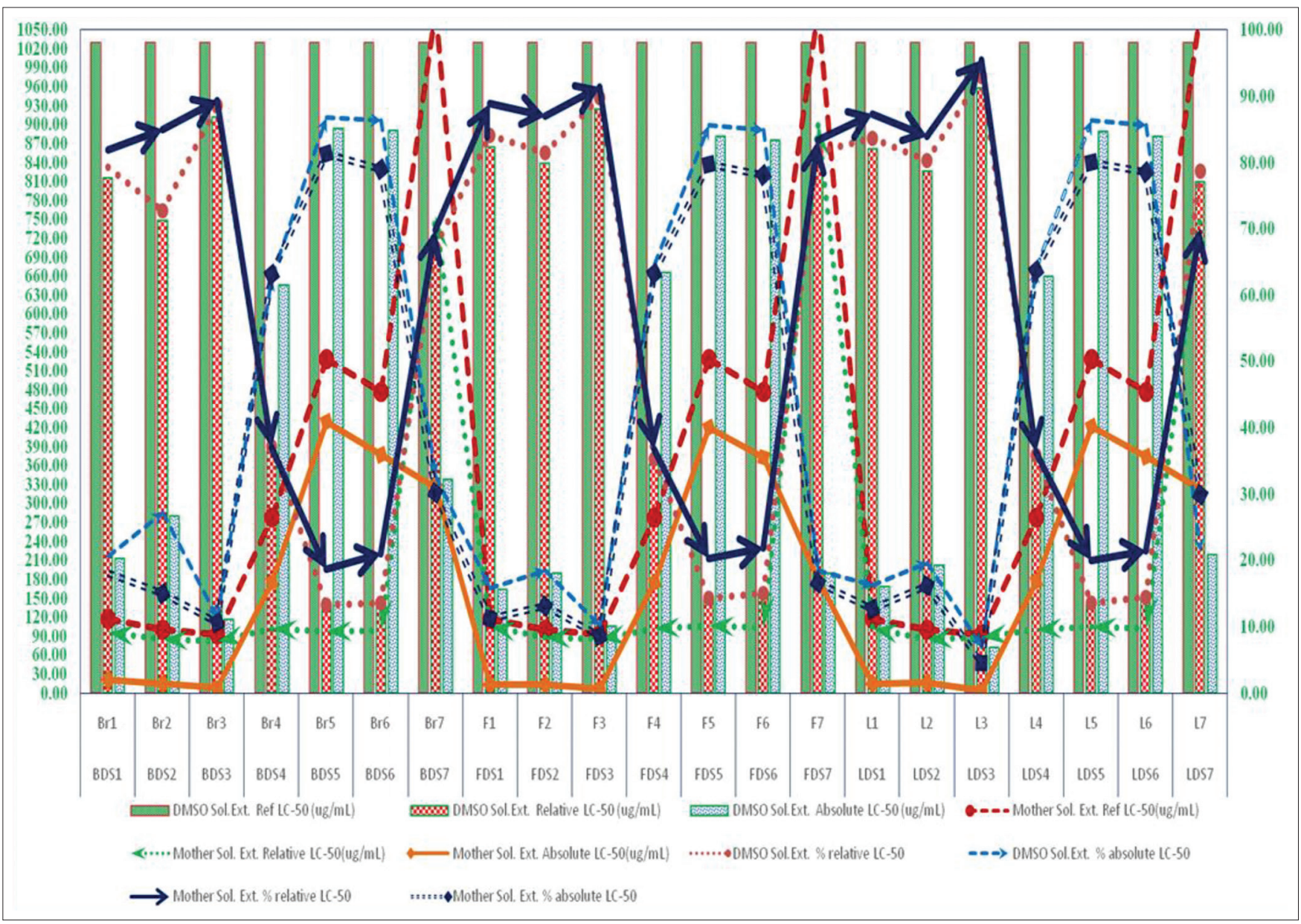

Fig 5. Showing comparative combined toxicological parameters for mother solvent extracts and DMSO solvent extracts. The primary and secondary, $\mathrm{X}$-axis reflecting solvent mother solvent extracts and DMSO solvent extracts, respectively. Primary Y-axis showing different toxicity classes where as secondary $\mathrm{Y}$-axis toxicity parameters to be represented in \%.

term (14 d) mortality as to be the prominent Artemia spp. protocols that might with stand to international standards. The deviation of the previous results from present study is also evidence that might be due to species specific nature, source of collection and treatment conditions. As far as the toxicity studies are concerned the Artemia salina used in the present study was found to achieve Instar stage II that recommended for toxicity studies as earlier stage are more resistant that may alter the actual results (Hamidi et al., 2014). In the present study total salt needed for preparing artificial sea water was provided in two installments of which approx. $75 \%$ as primary and $25 \%$ as secondary dose that were given next morning after setup of the hatching experiment. The possible reason behind the better result is the diffuse salt doses which could enhance. salt resistance to the species and thereafter provoked adaptive gene interactions which also providing strength and capacity to survive and actively move in the medium, and also provides filtered result of toxicity as the Artemia salina would be practically more harder than normal one After, hatching, the toxicity experiment was setup by picking up the nauplii of Artemia salina with $3 \mathrm{~mL}$ dropper that was cut at the tip to ensure hassle free required number of nauplii and put into $50 \mathrm{~mL}$ plastic container with optimized experimental conditions as mentioned above unlike to the previous studies who suggested to set up the toxicity testing either by pre-treating the Petri dish with light or short term light exposure for 1 hour and then incubation for 24 hours in dark (Artoxkit ${ }^{\circledR}$ 2014). This is in contrast to our study which used continuous light source that is supported by Sorgeloos, (1973) who noticed that light sensation was found to expedite hatching of brine shrimp cysts significantly and illustrated that embryological progression of hydrated embryos that are not ignited by light, can be interrupted till the light appear. As a thumb rule, hatching of cysts after light stimulus can make paramount differences for dark and light experimental conditions(Sorgeloos, 1973). The small deviation can make large differences while set up of experiments, for instances, picking the larvae with micropipette exert extraneous pressure while picking up the sensitive early stage of Artemia to reach instar II that is to be used for toxicity studies. The reason of suitable stage of Artemia has briefly illustrated 
by many researchers (Sorgeloos et al., 1978; Vanhacke and Persoone, 1984; Sleet and Brendel, 1985; Kokkali et al., 2011). It has been demonstrated that I instar is the only stage which can efficiently use yolk as a primary source for food supply and found to exhibit more tolerance against chromic acid, as this stage could not develop efficient digestive tract essential for felicitating absorption of incoming materials from the elementary canal. The Table 2 , is showing the comparative toxicological parameters of BSLA of T. arjuna solvent extracts. Most noticeably, in present study the author emphasized upon the finding that $\mathrm{LC}_{50}$ of the solvent extract are the relative $\mathrm{LC}_{50}$ correspond to the respective mother solvents and absolute value should be the actual value of the extract alone. As, it is known that negative control could be used for eliminating the other fraction contributing in the overall toxicity. The solvent system deployed to mix the evaporated plant materials is a relevant control for this purpose so actual value should be obtained when the $\mathrm{LC}_{50}$ of mother solvent to be deducted from relative $\mathrm{LC}_{50}$ of corresponding extract but present study indicates that mother solvent has more $\mathrm{LC}_{50}$ as compared to the solvent extract. If we take real value then absolute $\mathrm{LC}_{50}$ value of effective extract would be always in negative or if we take absolute value ignoring the sign then it would be higher than the relative $\mathrm{LC}_{50}$ Value of the solvent extracts. From the perusal of Fig. 4 and Table 2, it can be implied that relative $\mathrm{LC}_{50}$ and absolute $\mathrm{LC}_{50}$ has inverse relation that may likely due to the fact that relative $\mathrm{LC}_{50}$ value is toxicity contributed due to mother solvents and vice versa.

Fig. 6 showed that $\%$ relative $\mathrm{LC}_{50}$ values and $\%$ absolute value has negative correlation and similarly, relative $\mathrm{LC}_{50}$ value and Absolute $\mathrm{LC}_{50}$ values are negatively correlated, and reference $\mathrm{LC}_{50}$ that is the $\mathrm{LC}_{50}$ of mother solvents, are highly positively correlated with the absolute $\mathrm{LC}_{50}$ values. Among solvent extracts, the BDS4, FDS4, LDS4 and BDS5 \& 6; LDS 5 \& 6; FDS 5 $\& 6$ are highly correlated with reference $\mathrm{LC}_{50}$ values of solvent extracts.

Similarly, Fig. 7 showed the distribution pattern of solvent extracts and clearly depicting that effective extract exhibiting more absolute $\mathrm{LC}_{50}$ than the relative $\mathrm{LC}_{50}$ values. These results are in accordance to the Musa (2012) who has suggested that $\mathrm{LC}_{50}(240 \pm 3 \mu \mathrm{g} / \mathrm{mL})$ value of $80 \%$ acetone extract was found to be more effective as compared to n-butanol extract $\mathrm{LC}_{50}(437 \pm$ $8 \mu \mathrm{g} / \mathrm{mL}$ ). Similarly, the toxicity of ethanolic extract in other study also showed mild toxicity and considered as safe but in our study the ethanolic bark extract showed elevated toxicity might be due to presence of some of the active ingredients which is in conformity to the previous research (Tungmunnithum et al., 2018; Aryal et al., 2019).

In the present study, the polar solvents such as ethanol, methanol and water are; low, medium and non-toxic while in solvent extracts forms their toxicity nature gets changed to closed to highly toxic and as per the toxicity criterion it falls as medium toxic or highly toxic which not an proof of being safe or unsafe as far as their applications in human and other vertebrates are concerned. For instances, the T. arjuna are being used as aqueous hot extract (decotion) and crude forms are reported to be very much effective against chronic ailments and disease without negatively affecting the physiology of an organism (Chaudhari and Mahajan, 2015).

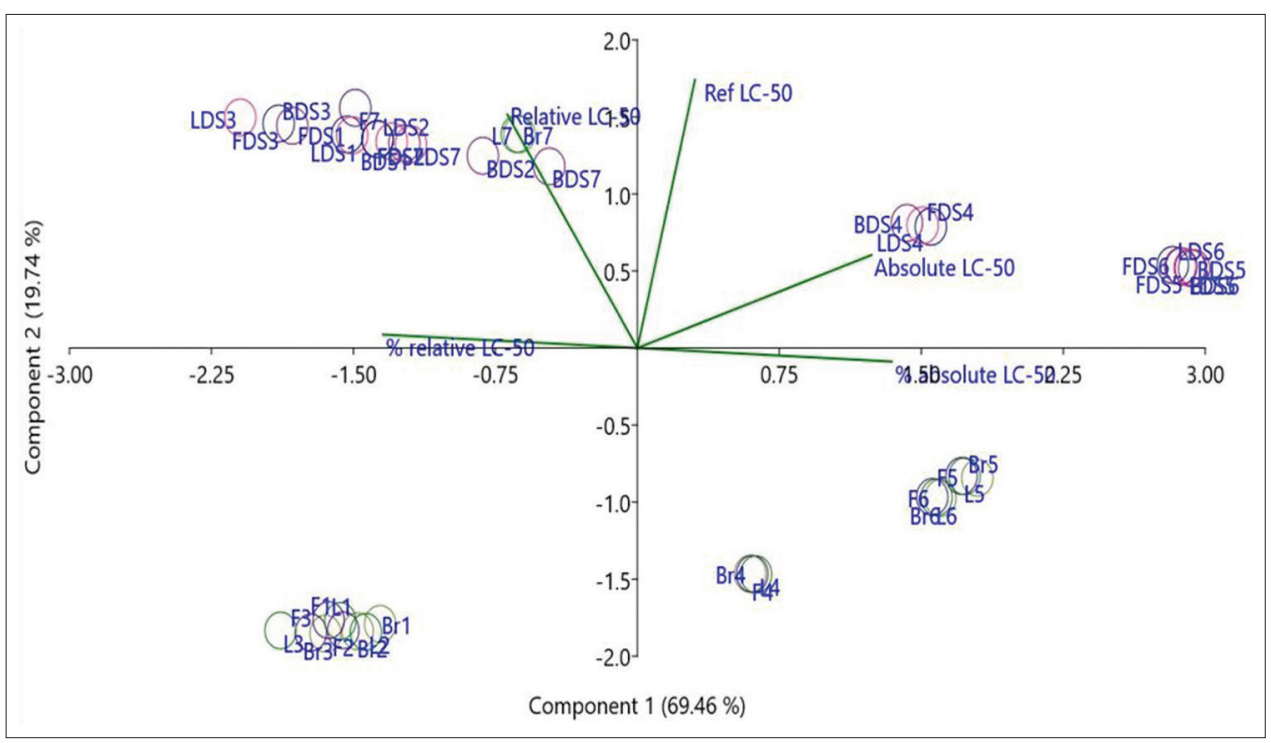

Fig 6. PCA bi-plot of T. arjuna solvent extract with toxicological parameters. Figure showing the correlation between solvent extracts and toxicological parameters. The PCA components explaining the variations among the parameters. 
Meena, et al.

Table 2: Showing the combined data of BSLA of $T$.arjuna solvent extracts

\begin{tabular}{|c|c|c|c|c|c|}
\hline & Ref $\mathrm{LC}_{50}$ & $\%$ relative $\mathrm{LC}_{50}$ & Relative $\mathrm{LC}_{50}$ & $\%$ absolute $\mathrm{LC}_{50}$ & Absolute LC $_{50}$ \\
\hline BDS1 & 1029.07 & 79.28 & 815.90 & 20.72 & *213.17 \\
\hline BDS2 & 1029.07 & 72.72 & 748.34 & 27.29 & *280.74 \\
\hline BDS3 & 1029.07 & 88.65 & 912.32 & 11.35 & *116.75 \\
\hline BDS4 & 1029.07 & 37.24 & 383.22 & 62.76 & **645.85 \\
\hline BDS5 & 1029.07 & 13.21 & 135.99 & 86.78 & **893.091 \\
\hline BDS6 & 1029.07 & 13.51 & 139.01 & 86.49 & ${ }^{* * 890.06}$ \\
\hline BDS7 & 1029.07 & 67.16 & 691.14 & 32.84 & *337.93 \\
\hline FDS1 & 1029.07 & 84.05 & 864.94 & 15.95 & *164.13 \\
\hline FDS2 & 1029.07 & 81.50 & 838.73 & 18.45 & *190.34 \\
\hline FDS3 & 1029.07 & 89.79 & 924.07 & 10.20 & ${ }^{*} 105.01$ \\
\hline FDS4 & 1029.07 & 35.24 & 362.63 & 64.76 & ${ }^{* *} 666.44$ \\
\hline FDS5 & 1029.07 & 14.28 & 146.98 & 85.72 & **882.09 \\
\hline FDS6 & 1029.07 & 15.01 & 154.37 & 84.99 & **874.71 \\
\hline FDS7 & 1029.07 & 81.54 & 839.09 & 18.46 & *189.97 \\
\hline LDS1 & 1029.07 & 83.65 & 860.78 & 16.35 & *168.29 \\
\hline LDS2 & 1029.07 & 80.34 & 826.76 & 19.66 & *202.31 \\
\hline LDS3 & 1029.07 & 93.01 & 957.15 & 6.98 & *71.92 \\
\hline LDS4 & 1029.07 & 35.93 & 369.78 & 64.06 & **659.29 \\
\hline LDS5 & 1029.07 & 13.59 & 139.94 & 86.40 & **889.13 \\
\hline LDS6 & 1029.07 & 14.38 & 147.95 & 85.62 & ${ }^{* *} 881.12$ \\
\hline LDS7 & 1029.07 & 78.73 & 810.22 & 21.26 & *218.85 \\
\hline $\mathrm{Br} 1$ & 118.51 & 81.93 & 97.09 & 18.06 & *21.41 \\
\hline $\mathrm{Br} 2$ & 101.75 & 84.97 & 86.45 & 15.02 & *15.29 \\
\hline $\mathrm{Br} 3$ & 93.35 & 89.39 & 83.45 & 10.61 & ${ }^{*} 9.91$ \\
\hline $\mathrm{Br} 4$ & 278.32 & 36.96 & 102.87 & 63.039 & *175.45 \\
\hline $\mathrm{Br} 5$ & 528.78 & 18.67 & 98.65 & 81.34 & **430.12 \\
\hline $\mathrm{Br} 6$ & 477.67 & 20.97 & 100.16 & 79.03 & **377.51 \\
\hline $\mathrm{Br} 7$ & 1081.29 & 69.89 & 755.59 & 30.12 & *325.71 \\
\hline $\mathrm{F} 1$ & 118.51 & 88.83 & 105.26 & 11.17 & *13.24 \\
\hline $\mathrm{F} 2$ & 101.75 & 86.94 & 88.46 & 13.06 & *13.28 \\
\hline F3 & 93.3 & 91.37 & 85.31 & 8.62 & *8.05 \\
\hline F4 & 278.32 & 36.69 & 102.13 & 63.31 & **176.19 \\
\hline F5 & 528.78 & 20.31 & 107.41 & 79.68 & **421.37 \\
\hline F6 & 477.67 & 21.85 & 104.36 & 78.15 & *373.31 \\
\hline F7 & 1081.29 & 83.32 & 900.94 & 16.68 & *180.36 \\
\hline L1 & 118.51 & 87.27 & 103.42 & 12.73 & *15.08 \\
\hline L2 & 101.75 & 83.88 & 85.35 & 16.12 & ${ }^{*} 16.40$ \\
\hline L3 & 93.36 & 95.51 & 89.16 & 4.49 & ${ }^{*} 4.19$ \\
\hline L4 & 278.32 & 36.25 & 100.89 & 63.75 & **177.43 \\
\hline L5 & 528.78 & 19.99 & 105.73 & 80.01 & **423.04 \\
\hline L6 & 477.67 & 21.39 & 102.19 & 78.61 & **375.48 \\
\hline L7 & 1081.29 & 70.09 & 757.99 & 29.90 & *323.31 \\
\hline
\end{tabular}

*Indicate the lower value of absolute $\mathrm{LC}_{50}$ as compared to relative $\mathrm{LC}_{50}$; ${ }^{* *}$ indicate the higher value of absolute $\mathrm{LC}_{50}$ as compared to relative $\mathrm{LC}_{50}$ 


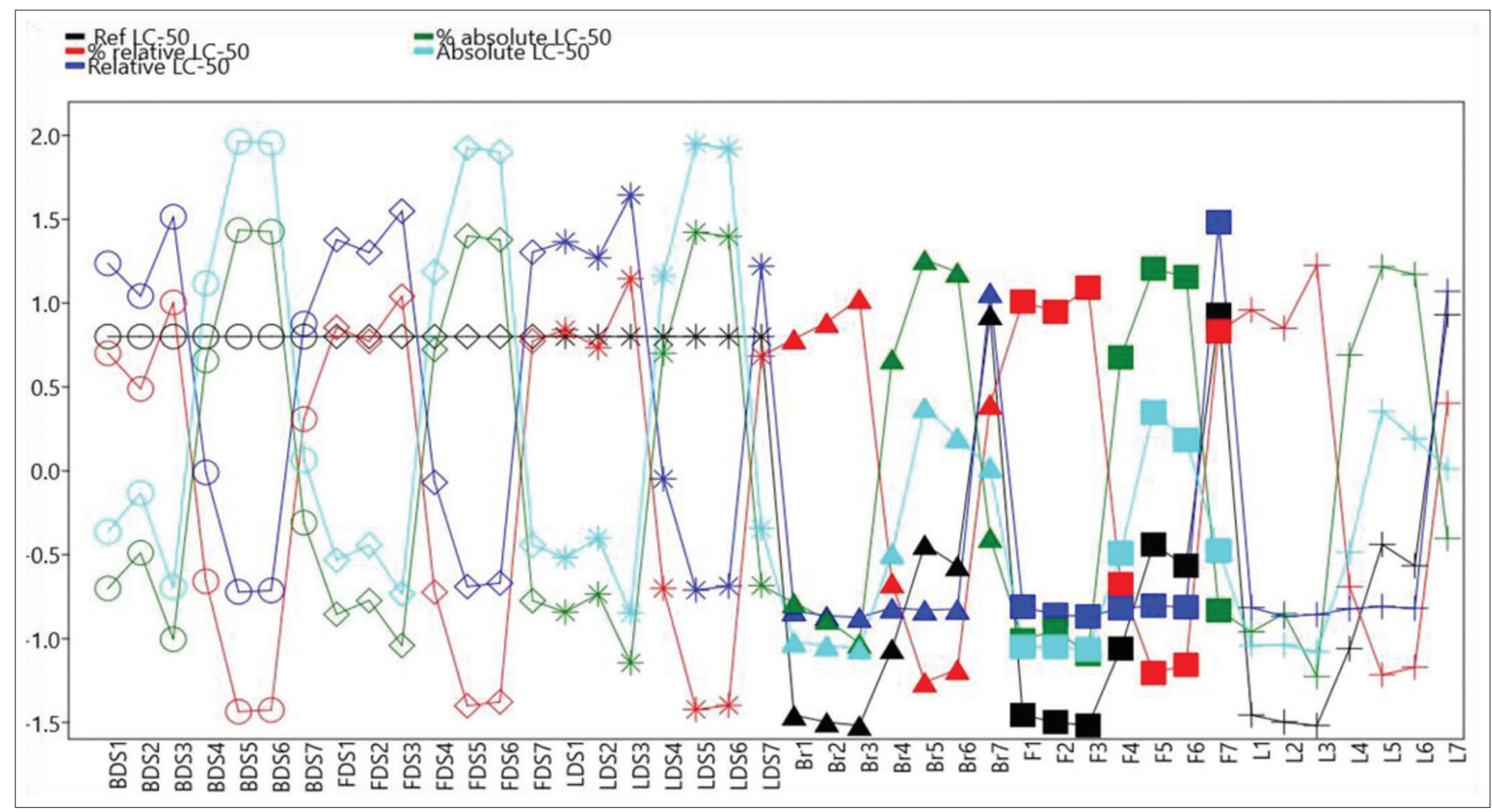

Fig 7. Distribution of toxicological parameters of $T$. arjuna solvent extracts by BSLA. Figure showing the competence of the effective solvent extracts in terms of exhibiting more absolute $\mathrm{LC}_{50}$ than the relative $\mathrm{LC}_{50}$ values.

\section{Perspectives}

1. A holistic approach is needed to streamline the unwind aspects of toxicity in context of classes of toxicity and to declare Artemia as globally accepted model in eco-toxicology involving institutional and regulatory mechanism enforced by regulatory and apex statutory body to define the toxicity level of unexplored aspects of safe and being toxic.

2. The toxicity studies should take lower and upper 95 $\%$ Fiducial Class interval into account while deciding the nature of the herbal extracts and corresponding $\mathrm{LC}_{50}$ value to be laid between and upper and lower limit.

3. The concept of relative and absolute $\mathrm{LC}_{50}$ need to be implemented so that the actual toxicity potential and strength of the herbal or solvent extracts can be plotted by eliminating the effects of negative control in toxicity assessment.

4. The study suggest that polar solvent extract of ethanol, methanol and distilled water found to be medium to low toxic, non-toxic which facilitates the possibility of their inclusion as mother solvents for extraction and as an alternate to DMSO for short term toxicity provided the relative and absolute $\mathrm{LC}_{50}$ are known for the solvent extracts.

5. The existing criterion and index of toxicity assessment need a through revision and modification in terms of fixing the toxicity of a particular extracts. For instances, in the present study, as per the Meyers toxicity index all solvent extract are found to be toxic except distilled water and DMSO whereas in Clarkson's criterion, the solvent extracts found to be taking places in different classes i.e. non, low, medium, and highly toxic. Some of the solvents were exhibited very narrow margin to a particular level and the range of toxicity level is too wide to define it properly, therefore, there is need to expand and define more classes considering the ethnomedicinal uses of a particular herbal material.

6. The toxicity criterion needs to be supplemented by the therapeutic index (TI) and EC $25 \%-\leq \mathrm{LC}_{50}$ value of solvent extracts while determine the toxicity nature of the extracts mere based on BSLA so that the declaration with regards to safety aspects and possibility of designing new drugs and medicine might be sound and reliable practice.

\section{CONCLUSION}

The BSLA study of solvent extracts of T. arjuna validated the toxicity nature of the corresponding solvent extracts with $\mathrm{LC}_{50}$ of brine shrimp, however, to enhance the robustness of the method, there is need to revisit the existing toxicity criterion in terms of actual $\mathrm{LC}_{50}$ value and the strength of the solvent extract. More scientifically, the inclusion of two new terminologies, relative and absolute $\mathrm{LC}_{50}$ should be in place. In addition, the consideration of absolute $\mathrm{LC}_{50}$ if the value exceeds from relative $\mathrm{LC}_{50}$, 
as potential of the solvent extract as being toxicant. The ethanolic and methanolic bark extracts could exhibit maximum absolute $\mathrm{LC}_{50} \%$ fractions out of total toxicity which showed their potential as safe therapeutic agents.

\section{Conflicts of interest}

Authors declare no conflicts of interest and any financial competitiveness for the present work. The research is an original work neither published nor under consideration for publication anywhere.

\section{Contribution of the author}

B. K. Das: Designed and monitored the research work; N. P. Sahu: Designed and checked draft manuscript; P.P. Srivastava: Designed the experiment; A. K. Sahoo: Manuscript preparation and data analysis: D. K. Meena: Research, draft manuscript preparation and statistical analysis: S. Borah: Data analysis; H.S. Swain: Artemia culture.

\section{ACKNOWLEDGEMENT}

The support rendered by the lab staff and hatchery personnel is highly acknowledged.

\section{REFERENCES}

Arslanyolu, M. and F. Z. Erdemgil. 2006. Evaluation of the antibacterial activity and toxicity of isolated arctiin from the seeds of Centaurea sclerolepis. J. Fac. Pharm. 35: 103-109.

Artoxkit ${ }^{\circledR}$. 2014. Available from: http://www.microbiotests.be/toxkits/ artoxkit.pdf. [Last accessed on 2014 Apr 28].

Aryal, S., M. K. Baniya, K. Danekhu, P. Kunwar, R. Gurung and N. Koirala. 2019. Total phenolic content, flavonoid content and antioxidant potential of wild vegetables from Western Nepal. Plants. 8: 96.

Bhatt, I. D., P. Dauthal, S. Rawat, K. Gaira, A. Jugran, R. S. Rawal and U. Dhar. 2012. Characterization of essential oil composition, phenolic content and antioxidant properties in wild and planted individuals of Valeriana jatamansi Jones. Sci. Hortic. 136: 61-68.

Campbell, D. L., L. A. Lawton, K. A. Beattie and G. A. Codd. 1994. Comparative assessment of the specificity of the brine shrimp and microtox assays to hepatotoxic (microcystin-LRcontaining) cyanobacteria. Environ. Tox. 9: 71-77.

Chaudhari, G. M. and R. T. Mahajan. 2015. Comprehensive study on pharmacognostic, physico and phytochemical evaluation of Terminalia arjuna Roxb. Stem bark. J. Pharmacog. Phytochem. 4(3): 186-193.

Clarkson, C., V. J. Maharaj, N. R. Crouch, O. M. Grace, P. Pillay, M. G. Matsabisa, N. Bhagwandin, P. J. Smith and P. I. Folb. 2004. In vitro antiplasmodial activity of medicinal plants native to or naturalized in South Africa. J. Ethnopharm. 92: 177-191.

Dvorak, P., K. Benova and J. Vitek. 2012. Alternative biotest on Artemia franciscana. J. Ecotoxicol. Environ. Saf. 3: 51-74.

Gadir, S. A. 2012. Assessment of bioactivity of some Sudanese medicinal plants using brine shrimp (Artemia salina) lethality assay. J. Chem. Pharm. Res. 4: 5145-5148.

Hamidi, M. R., B. Jovanova and T. K. Panovska. 2014. Toxicological evaluation of the plant products using brine shrimp (Artemia salina L.) model. Mecedonian Pharm. Bull. 60(1): 9-18.

Kokkali, V., I. Katramados and J. D. Newman. 2011. Monitoring the effect of metal ions on the mobility of Artemia salina Nauplii. Biosensors. 1: 36-45.

Lee, K. H. 1992. Plant Phenolic Compounds as Cytotoxic Antitumor Agents. In: Phenolic Compounds in Food and Their Effects on Health II. ACS Symposium Series. American Chemical Society, pp. 367-379.

Libralato, G., E. Prato, L. Migliore, A. M. Cicero and L. Manfra. 2016. A review of toxicity testing protocols and endpoints with Artemia spp. Ecol. Indic. 69: 35-49.

Manfra, L., C. Maggi, J. Bianchi, M. Mannozzi, O. Faraponova, L. Mariani, A. Mueller, S. K. Bopp and G. Umlauf, G. 2010. Toxicity evaluation of produced formation waters after filtration treatment. Nat. Sci. 2(1): 33-40.

Manfra, L., F. Savorelli, L. B. Di, G. Libralato, S. Comin and D. Conti and E. Prato. 2015. Inter calibration of ecotoxicity testing protocols with Artemia franciscana. Ecol. Indicat. 57: 41-47.

Manfra, L., N. E. De, C. Maggi, E. Zambianchi, D. Caramiello, A. Toscano and D. Cianelli. 2011. Exposure of rotifers, crustaceans and sea urchins to produced formation waters and seawaters in the Mediterranean Sea. J. Mar. Biol. Assoc. UK. 91(1): 155-161.

Martínez, M., J. Del Ramo, A.Torreblanca and J. Díaz-Mayans. 1999. Effect of cadmium exposure on zinc levels in the brine shrimp Artemia parthenogenetica. Aquaculture. 172: 315-325.

Maurer-Jones, M. A., S. A. Love, S. Meierhofer, B. J. Marquis, Z. Liu and C. L. Haynes. 2013. Toxicity of nanoparticles to brine shrimp: An introduction to nanotoxicity and interdisciplinary science. J. Chem. Educ. 90: 475-478.

Mayorga, P., K. R. Pérez, S. M. Cruz and A. Cáceres. 2010. Comparison of bioassays using the anostracan crustaceans Artemia salina and Thamnocephalus platyurus for plant extract toxicity screening. Bras. J. Pharm. 20: 897-903.

McLaughlin, J. L., L. L. Rogers and J. E. Anderson. 1998. The use of biological assays to evaluate botanicals. Drug Inf. J. 32: 513-524.

Meyer, B. N., N. R. Ferrigni, J. E. Putnam, L. B. Jacobsen, D. E. Nichols and J. L. McLaughlin. 1982. Brine Shrimp: A convenient general bioassay for active plant constituents. Planta Medica. 45: 31-34.

Moshi, M. J., E. Innocent, J. J. Magadula, D. F. Otieno, A. Weisheit, P. K. Mbabazi and R. S. O. Nondo 2010. Brine shrimp toxicity of some plants used as traditional medicines in Kagera Region, North Western Tanzania. Tanzan. J. Health Res. 12: 63-67.

Musa, A. A. 2012. Cytotoxicity activity and phytochemical screening of Cochlospermum tinctorium Perr Ex A. rich rhizome. J. Appl. Pharma. Sci. 2(7): 155-159.

Naidu, J. R., R. Ismail and S. Sasidharan. 2014. Acute oral toxicity and brine shrimp lethality of methanol extract of Mentha spicata L. (Lamiaceae). Trop. J. Pharm. Res. 13: 101-107.

Nunes, B. S., F. D. Carvalho, L. M. Guilhermino and G. Van Stappen. 2006. Use of the genus Artemia in ecotoxicity testing. Environ. Pollut. 144(2): 453-462.

Ogugu, S. E., A. J. Kehinde, B. I. James and D. K. Paul. 2012. Assessment of cytotoxic effects of methanol extract of Calliandra portoricensis using brine shrimp (Artemia salina) lethality bioassay. Glob. J. Bio Sci. Biotech. 2: 257-260.

Parra, L. A., R. S. Yhebra, I. G. Sardiñas and L. I. Buela. 2001. Comparative study of the assay of Artemia salina L. and the estimate of the medium lethal dose (LD50 value) in mice, to determine oral acute toxicity of plant extracts. Phytomedicine. 8: 395-400.

Pelka, M., C. Danzl, W. Distler and A. Petschelt. 2000. A new 
screening test for toxicity testing of dental materials. J. Dent. 28: 341-345.

Ren, W., Z. Qiao, H. Wang, L. Zhu and L. Zhang. 2003. Flavonoids: Promising anticancer agents. Med. Res. Rev. 23(4): 519-534.

Sharma, N., P. C. Gupta, A. Singh and C. V. Rao. 2013. Brine shrimp bioassay of Pentapetes phoenicea Linn. and Ipomoea carnea Jacq. leaves. Pharm. Lett. 5: 162-167.

Solanki, S. S. and M. Selvanayagam. 2013. Phytochemical screening and study of predictive toxicity of certain medicinal plants and extracts using brine shrimp. J. Herb. Sci. Tech. 10: 1-4.

Suely, A., H. Zabed, A. B. Ahmed., J. Mohamad, M. Nasiruddin, J. N. Sahu and P. Ganesan. 2015. Toxicological and hematological effect of Terminalia arjuna bark extract on a freshwater catfish, Heteropneustes fossilis. Fish Physiol. Biochem. 42(2): 431-44.

Sushant, A., M. K. Baniya, D. Krisha, P. Kunwar, R. Gurung and N. Koirala. 2019. Total phenolic content, flavonoid content and antioxidant potential of wild vegetables from Western Nepal. Plants. 8(96): 1-12.

Tungmunnithum, D., A. Thongboonyou, A. Pholboon, and A. Yangsabai 2018. Flavonoids and other phenolic compounds from medicinal plants for pharmaceutical and medical aspects: An overview. Medicine. 5(3): 93.

Van, S. M. and G. Persoone. 1993. Cyst-based toxicity tests V. development and critical evaluation of standardized toxicity tests with the brine shrimp Artemia (Anostraca, Crustacea). In: A. M. V. Soares . and P. Calow. (Eds.), Progress in Standardization of Aquatic Toxicity Tests. Lewis Publishers, Boca Raton, pp. 81-97.

Vanhaecke, P., G. Persoone, C. Claus and P. Sorgeloos. 1980. Research on the development of a short-term standard toxicity test with Artemia. The brine shrimp Artemia. In: Ecology, Culturing, Use in Aquacult. Vol. 1. Universa Press, Wetteren, Belgium, pp. 263-285.

Vanhaecke, P., G. Persoone, C. Claus and P. Sorgeloos. 1981. Proposal for a short-term toxicity test with Artemia nauplii. Ecotoxicol. Environ. Saf. 5(3): 382-387.

WHO. 2007. Department of Technical Cooperation for Essential Drugs and Traditional Medicine. Guidelines for Assessing Quality of Herbal Medicines with Reference to Contaminants and Residues. World Health Organization, Geneva.

Worthley, E. G. and C. D. Schott. 1969. The toxicity of four concentrations of DMSO. Toxicol. Appl. Pharmacol. 15: 275-281.

Wu, C. 2014. An important player in brine shrimp lethality bioassay: The solvent. J. Adv. Pharm. Technol. Res. 5: 57-65.

Yu, J. and Y. Lu. 2018. Artemia spp. Model-a well established method for rapidly assessing the toxicity on an environmental perspective. Med. Res. Arc. 6(2): 1-15. 